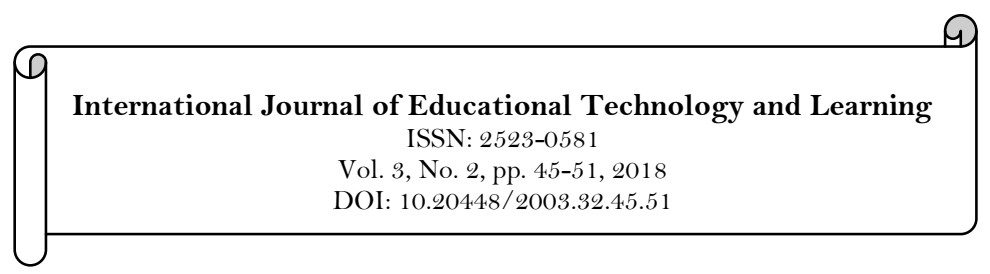

\title{
Awareness and Utilization of e-Learning Resources by Trainee Counsellors of Counselling Education in Calabar, Nigeria
}

\author{
Okpechi, P.A ${ }^{1}$ \\ Denwigwe, C. P. ${ }^{2}$ \\ Asuquo, P.N. ${ }^{3}$ \\ Abuo, C. ${ }^{4}$ \\ Unimna, F.U. ${ }^{5}$ \\ 1,2,3,4,5 Guidance and Counselling Department, University of Calabar, PMB115 Calabar - Nigeria. \\ ${ }^{3}$ Email:patasu001@yahoo.com
}

\begin{abstract}
In Nigeria, electronic-learning (e-learning) resources have emerged as a modern tool for enhancing the quality of delivery and acquisition of education content. Yet, hardly has there been any meaningful research report on the application of this innovative and invaluable tool to counselling education service delivery efforts. This study, 'awareness and utilization of e-learning resources by trainee Counsellors in counselling education in Calabar, Nigeria' was designed to fill this literature gap. A structured questionnaire with reliability index of 0.83 titled "Awareness and Utilization of Elearning Questionnaire (AUEQ)" was used to collect data from a sample of 300 students and analyzed using t-test statistics. The results of the study indicate that while the awareness of e-learning resources by trainee Counsellors was generally high, their rating in terms of availability, currency, adequacy and quality of these resources within their schools was rather very low. The results also indicated that the extent of utilization of e-learning was also very insignificant. Furthermore, the outcomes of the study show interclass, inter-school and inter-gender differences with regards to both awareness of availability and utilization of e-learning resources. Based on the findings, it was recommended that Universities and other higher education settings should be equipped with current, functional and adequate e-learning resources for enhanced service delivery. It was also recommended that both counsellor educators and trainees should be systematically trained in appropriate skills required for the use of e-learning facilities. It was further recommended that assurance of constant and adequate power supply should be improved upon to enhance the use of e-learning in our Universities.
\end{abstract}

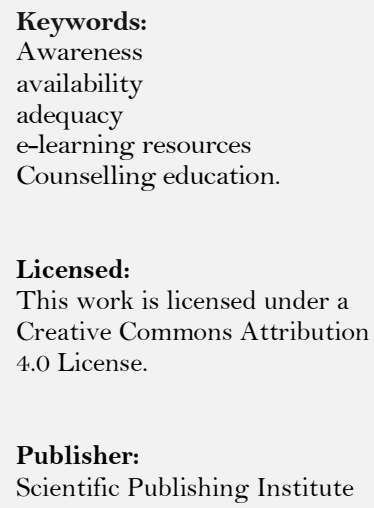

Licensed:

This work is licensed under a

Creative Commons Attribution

4.0 License.

Publisher:

Scientific Publishing Institute

\section{Introduction}

In Nigeria, universities were originally established to provide quality high education that facilitates creation of new knowledge, innovation and technologies for the overall individuals' socio-economic development and also for national well being and integration. Guidance and Counselling as an ancilliary service, oriented towards making life work, the school system functional, labour market viable and ultimately, the nation productive, was introduced to enhance the quality of education at all levels. Regardless of its type or stage, the bottom-line in all quality education is the production of functional citizens imbued with relevant knowledge, values, attitudes and skills to make them useful to themselves and have capacity to contribute meaningfully to the well being of their society. The prime objective of every quality education process, therefore, is to ensure the acquisition of appropriate and relevant knowledge, skills, competences, values and attitudes by those who patronize these schemes. The university system in Nigeria today, seems to be a far cry 
from this humane ideal of the founding fathers as it has generally been ill-equipped and tended to become characterized by dwindling appetite for reading, unfavourable attitude to learning and poor research orientation (Asuquo, 2015). This unfortunate state of things to some extent can partly be blamed on the process that delivers instruction and the mode of acquiring knowledge and skills in most universities in Nigeria which have over the years remained basically stagnant, archaic and comparatively obsolete with its likely effect of the producing largely illiterate, half-baked and less competent graduates has gradually become the norm (Asuquos, 2017).

This is, however, happening at a time when education is increasingly becoming recognized globally by all well meaning societies as a veritable channel through which every society seeks to prepare its young for responsive, productive and prosperous adult living. Education in such climes encompasses amongst others; a sound or solid foundation of literacy, numeracy, lifelong learning, equal opportunity, personal fulfilment, quality of life enrichment, social cohesion, critical thinking and social skills - all of which make for responsible citizenship (Asuquos, 2017).

The apparent lack of these basic ingredients of quality in our education service delivery at all levels has tended to discourage and even disillusion many aspirants to and recipients of education. Many young people seem to be questioning the whole essence and relevance of education and what it has to offer. Parents who bear the brunt of sacrificing to enable their children acquire appropriate education appear hard hit by current trends in the formal education system. Little wonder that the more able amongst them have taken the option of sending their wards to private universities within Nigeria or to those abroad. Similarly, employers of labour who largely utilize products of the Nigerian university system are lamenting the general nature of the unemployability of university graduates who lack the basic requisite knowledge and skills purported to have been acquired in the course of their education which would have predisposed them to be engaged productively. Government and non-governmental organizations alike are quick to point out deficits knowledge and skill gaps in our economy which should have been bridged by the ever increasing number of graduates churned out annually from our university system. Operators of the system vis-à-vis practitioners at the teaching and learning levels continue to worry about appropriate measures and interventionist schemes to be introduced to check the drift in the Nigerian university system.

The emergence and prevalence of new technologies in our society today which have to some extent affected our lives, daily living and life activities in tremendous ways seem to be a veritable option. For the past two decades or more, electronic-devices and their systems have practically influenced all facets of life, including our values, beliefs, culture, religion and total way of life. The effects of these devices and their accompanying systems are quite discernable in all functional sectors of the Nigerian society, namely, commerce and industry, manufacturing processes, social and educational systems. While enlightened societies across the globe are adopting these new technologies to solve the challenges of life that confront them and in particular adapting their educational systems in response to the exigencies of the new devices, Nigeria is yet to fully embrace them. E-learning resources are a powerful tool that could be harnessed and used to enhance and encourage teaching and learning process in the universities. They should be accepted, applied and kept abreast with in all areas of our teaching and learning endeavours. More so as the world strives to meet development goals with increasing recognition of the potential of e-learning resources to meet growing educational challenges, counsellors are expected to play vital roles. Therefore, the application of e-learning resources within the context of teaching and learning process in Counselling education service delivery has become doubly necessary especially in Nigeria today where emphasis is being placed on technological development.

\subsection{Conceptualization of Basic Terms and Related Literature}

Information Communication Technology (ICT) refers to the totality of methods and tools that are used in gathering, storing, processing and communicating information. It has found application in virtually all the available professions in the world. Professionals in different fields call it by different names. When ICT is used in education or to foster learning, it is called E-learning Technology or Educational Technology. According to Bamidele (2006) ICT is a revolution that involves the use of computers, internet and other telecommunication technology in every aspect of human endeavour. He posited that ICT is about sharing and having access to data with ease. This implies that ICT provides the super highway through which information is seamlessly transmitted and shared by people all over the world. Ofodu (2007) has also presented ICT as electronic or computerized devices, assisted by human and interactive materials that can be used for a wide range of teaching and learning as well as for personal use. In the broadcasting profession where ICT is used as a communication tool, it is commonly referred to as electronics information technology or just communication technology. A careful consideration of the meaning and scope of ICT makes it easy to think that hardly can any profession survive or continue to be relevant without the integration of ICT. ICT encompasses all the technologies used to transmit or disseminate information to an audience. These cover internet services provision, telecommunications equipment and services, media and broadcasting and other related information and communication activities. Modern ICT products include e-mail, voice mail, FAX, internet, electronic bulletin boards, cellular phones, videoconferencing among others. 
E-learning, according to Kasse and Blunywa (2013) as opposed to distance learning is a term that is used to refer to all ICT technologies, networks, internet and other forms of electronic media that can be used to enhance teaching and learning so as to transfer knowledge and skills. Therefore, e-learning resources are an inclusive term that describes educational technology that electronically or technologically supports learning and teaching (Parks, 2013). The developments in internet and multimedia technologies are the basic enablers of e-learning, with consulting, content, technologies, services and support being identified as the five key sectors of the e-learning industry. In learning and education, it involves the use of modern technologies such as computers, digital technology, networked digital device (e.g. the internet) and associated software and course ware. However, Philip (2003) clearly submitted that the organizational ability to learn and subsequent applications of learnt concepts could determine its survival, progress, development and proper ranking of institutions in the world global competitive markets.

Regardless of the educational level or stage, e-learning resources can be adopted, used or applied in the education for effective counselling skills, teaching and learning of undergraduates in Nigeria's universities. The advantage of these resources is that they are learner-centred, learner-controlled, and self-paced education process where learners have authority over their learning environment; thereby allowing them to work at their pace and convenience (Eke, 2011). Additionally, it is in line with the paradigm shift from teacher centredness to learner centredness (Kasse \& Blunywa, 2013). Daniel (2009) observed that e-learning plays an important role in professional development for adults in the workforce. The extent to which e-learning resources assist or replace other learning and teaching approaches is varied ranging on a continuum from none to fully online distance learning (Bates \& Poole, 2013). Kozma (2005) observed that ICT is now perceived as a principal driver of economic development and social change, worldwide. It offers the potential to restructure organizations, promotes collaboration, increases democratic participation of citizens, and improves transparency and responsiveness of governmental agencies. It also makes education and health care more widely available, fosters culture of creativity, and enhances the social integration of individuals with people of different abilities and cultural backgrounds. Farrel and Shafika (2007) also noted that there are widespread beliefs that ICT can be an important tool to introduce and sustain education reform efforts in Africa. These advantages notwithstanding, if the facilities are not available, adequate or current, it is almost doubtful that their potential benefits can be felt. Similarly, if the available resources are not utilized, it is also impossible to harvest any meaningful benefits.

Other variables of the present study that have been focused on in earlier researches include the awareness of the nature and scope, value, impact and effective methods of information and their utilization on Literacy skills instructions. The emphasis has been on the need to focus on the use of an integrated approach in all aspects of education with respect to new technologies, strategies and organizations. Aguolu and Aguolu (2002) have expressed the fear that e-learning resources may be available in the library and identified in the bibliography of the library as relevant to one's subject of interest, but the user may not be aware or let alone able to use them. The author went further to suggest that the more aware students are and accessible information resources are the more likely they are to be used. This connotes that awareness of availability and access to resource are critical determinants of their usability. In particular, and as usual in the case with introduction of new schemes or innovations, students may find it difficult to migrate from the traditional learning mode to the use of new e-learning resources (Asuquos, 2017). Clearly then, different people from different background exhibit different attitudes to certain things, issues and objects especially when it has to do with being receptive to change. Nwaoku (2005) stated that attitudes that define awareness, usability and accessibility have cognitive and mental components made up of concepts and beliefs. He emphasized that in Rivers State where he undertook his study, accessibility to e-learning resources was insignificant in public schools but a significant factor in private schools.

The Australian and New Zealand information literacy framework (2004) postulated that curriculum integration is the best approach for developing information literacy and that curriculum, classes and activities should be developed jointly by faculty and librarians to achieve course objectives and outcomes. Orr, Appleton, and Wallin (2001) in Central Queensland University (CQU) developed a framework on information literacy philosophy and flexible delivery that can be applied to all areas of education. The model identifies the need to integrate information literacy-use-instruction across the subjects for undergraduate students from varied background and linking them to the ever changing world of information resources, understand and utilize both the traditional catalogue and the online catalogue on e-learning resources.

Earlier, Onyejemezi (1988) in a study on "Educational Technology in Nigerian Education" asserted that the reasons why available instructional materials (e-learning resources) are not used in various secondary schools in Nigeria is because students do not know about their existences and therefore lack the necessary skills and competence to operate the e-learning resources. Wilson and Whitelock (1998) observed that nowadays, education organizations cannot exclude themselves from information society, being always confronted with new technological challenges. The student population comes from different social backgrounds, with different needs and expectations. Moreover, society is demanding for more qualified technicians. Schools are therefore, faced with a new technological paradigm, a new kind of public and new demands from society. 


\subsection{Rational and Purpose of the Present Study}

The application of e-learning resources to instructional delivery and acquisition of Guidance and Counselling content for enhanced students' performance remains very topical, relevant and important issue. However, there is little or no systematic studies that seek to verify the status and level of awareness of their availability by Counsellor trainees. Also, despite the critical potential of these resources to Nigeria's educational system in general, there have been no studies appraising individual students' subjective response to their availability and utilization using a Nigerian sample. The under representation of coherent research data on such critical topic in research literature continue to deny policy makers, planners, researchers and practitioners vital data. Against this background, the present study looks at awareness, availability and utilization of e-learning resources by Counsellor trainees in the course of acquiring of Counselling education content. The basic assumption was that the level of awareness to a large extent determines the perceived availability and also influences utilization. In other words, the paper focused on whether counsellor trainees have low or high awareness and/or whether perceived availability and utilization of these resources in learning is high or low as well as spread across gender, class and school. Data collected from trainee Counsellors were used to address three basic questions: (i) Is the awareness of e-learning resources high or low? (ii) What is the extent of utilization of e-learning resources? (iii) Are their rating of availability in terms of adequacy, currency and quality across gender, class and school? Specific hypotheses tested in the study were:

(1) HO1 Trainee counsellors' awareness of e-learning is not significantly high

(2) Ho2 Trainee counsellors' perceived utilization of e-learning resources is not significantly high

(3) Ho3 There are no significant differences in the rating of availability and utilization by trainee counsellors across gender, class and school

\section{Methodology}

The design for the study was survey. Stratified random sampling technique was used to select a sample of 300 trainee counsellors from the two universities within Calabar metropolis. The sample comprised 164 students from University of Calabar (UNICAL) and 136 from Cross River State University (CRUTECH); 126 males and 174 females, 142 final year class and 158 penultimate year. A questionnaire with reliability index of 0.83 titled "Awareness and Utilization of E-learning Questionnaire (AUEQ)" designed by the researchers and validated by experts in Counselling and Evaluation was the main instrument for data collection. The four point Likert-like scale instrument was divided into two parts. Section A contained information regarding respondents' gender, class level and school while B contained information pertaining to awareness, availability, adequacy, currency and utilization. With the help of some research assistants, the copies of questionnaire were administered directly on the respondents, who were guided on how to complete the questionnaire. Through manual scoring, positive statements were scored 4, 3. 2, and 1 points respectively for strongly agree, agree, strongly disagree, and disagree while the scoring order was reversed for negatively-worded items. The sum of scores for each respondent for the individual items was generated and subjected to further analysis using t-test statistics.

\subsection{Results of the Study}

The results of data analysis based on the objective of the study are presented in Tables 1 through 6 .

Table-1. Population t-test analysis of awareness of e-learning in counsellor Education by trainee counsellors ( $\mathrm{N}=300)$.

\begin{tabular}{l|l|l|l|l|l|l}
\hline Variable & $\mathbf{N}$ & $\overline{\mathbf{x}}$ & $\mathbf{S . D}$ & $\boldsymbol{\mu}$ & $\mathbf{D f}$ & $\mathbf{t}-\mathbf{c a l}$ \\
\hline Awareness of e-learning resources & 300 & 43.1 & 6.88 & 12.5 & 299 & $9.2 *$ \\
\hline $\mathrm{P}<.05, \mathrm{df}=299$, critical t-value $=1.98$.
\end{tabular}

Table 1 presents a brief summary of subjects' responses to the items measuring awareness of e-learning resources among trainee counsellors. The result as presented on Table 1 revealed that the calculated t-value was 9.2 while the critical value was 1.98 at .05 level of significance with 299 degrees of freedom. As the calculated t-value was greater than the critical t-value the null hypothesis was therefore, rejected. With this result, it can be concluded that the awareness of e-learning by trainee Counsellors in Counsellor education is significantly high.

Ho2 Trainee Counsellors' rating of availability of e-learning in counsellor education within their respective institutions was not significantly high. The key variable in this hypothesis was the rating of availability including adequacy, currency and quality of e-learning resources in counsellor's education. To test this hypothesis, population t-test was used and the result is as presented on Table 2.

Table-2. Population t-test analysis of the rating of availability of e-learning resources in counsellors' education within their respective institutions.

\begin{tabular}{l|l|l|l|l|l|l}
\hline Variable & $\mathbf{N}$ & $\mathbf{x}$ & S.D & $\boldsymbol{\mu}$ & Df & t-cal \\
\hline Availability of e-learning resources & 300 & 1.70 & 1.02 & 12.5 & 299 & 1.27 \\
\hline $\mathrm{P}<0.05, \mathrm{df}=299$, critical t-value $=1.98$.
\end{tabular}


The result in Table 2 reveals the difference between the calculated ( $\mathrm{t}-\mathrm{cal}$ ) and the critical $\mathrm{t}$ values (cri-t). The result showed that the calculated t-value of 1.27 is less than the critical t-value (1.98) at 299 degree of freedom and.05 level of significance. Since the calculated value is less than the critical t-value, the null hypothesis was retained. This implies that the rating of availability of e-learning resources in counsellor education content acquisition is rather very low.

Table-3. Population t-test analysis of utilization of e-learning resources in counsellors' education.

\begin{tabular}{l|l|l|l|l|l|l}
\hline Variable & $\mathbf{N}$ & $\mathbf{x}$ & $\mathbf{S . D}$ & $\boldsymbol{\mu}$ & $\mathbf{D f}$ & $\mathbf{t}-\mathbf{c a l}$ \\
\hline Utilization of e-learning resources & 300 & 1.40 & 1.00 & 12.5 & 299 & 1.24 \\
\hline $\mathrm{P}<.05, \mathrm{df}=299$, critical t-value $=1.98$.
\end{tabular}

Table 3 presents a brief summary of subjects' responses to the items measuring utilization of e-learning resources among trainee counsellors. The result as presented on Table 3 revealed that the calculated t-value of 1.24 is less than the critical value of 1.98 at.05 level of significance with 299 degrees of freedom. These results indicate that the trainee-counsellors used for this study tend to demonstrate poor application of e-learning resources to acquisition of counselling education content. These results indicate that though knowledge and awareness level of e-learning resources of CounselIors-in -training is high but the application to their learning of Counselling content is very low.

Table-4. Independent t-test analysis of gender differences in the rating of availability and utilization of e-learning resources in counselling education $(n=300)$.

\begin{tabular}{l|l|l|l|l|l}
\hline Variable & $\mathbf{n}$ & Mean & SD & Df & t-value \\
\hline Male & 122 & 18.48 & 3.81 & & 298 \\
\hline & & & & 3.18 & \\
\hline Female & 178 & 21.44 & & \\
\hline $\mathrm{P}<.05, \mathrm{df}=299$, critical t-value $=1.98$.
\end{tabular}

Table 4 presents the summary of independent t-test analysis of gender differences in the rating availability and utilization of e-learning in the acquisition counselling education content. The result on the table indicated that the mean value for males $(X=18.48)$ is less than the mean value of females $(X=21.44)$. Comparing the mean differences using independent t-test, the result revealed that the calculated t-value of 7.365 was greater than the critical t-value of 1.96 at 0.05 level of significance with 298 degrees of freedom. Based on this result, the null hypothesis 1 was rejected. This implies that the rating by female respondents in terms of availability and utilization of e-learning in Counselling education content acquisition was higher than that of their mail counterparts

Table-5. Independent t-test analysis of inter-class difference in the rating of availability and utilization of e-learning resources for acquisition of Counselling education content $(\mathrm{n}=300)$.

\begin{tabular}{lccccc}
\hline Variable & $\mathbf{n}$ & Mean & SD & df & t-cal \\
\hline Penultimate class & 165 & 18.89 & 3.48 & & \\
& & & & 298 & 3.612 \\
Ultimate class & 135 & 20.60 & 3.90 & & \\
\hline
\end{tabular}

$\mathrm{P}<.05, \mathrm{df}=299$, critical t-value $=1.98$

Table 5 presents the summary of independent t-test analysis interclass difference in the respondents' rating of availability and utilization of e-learning in Counselling education. The result on the table indicated that the mean value for penultimate class $(\mathrm{X}=18.89)$ is less than the mean value of the ultimate class $(\mathrm{X}=20.60)$. This shows that the rating of the penultimate class was less than that of the ultimate class. Comparing the mean differences using independent t-test, the result revealed that the calculated t-value of 3.612 was greater than the critical t-value of 1.96 at 0.05 level of significance with 298 degrees of freedom. Based on this result, the null hypothesis 2 was rejected. This implies that class level influences the respondents' rating of availability and utilization of e-learning resources in counselling education.

Table-6. Independent t-test analysis of inter-school differences in the rating of availability and utilization of e-learning resources for acquisition of Counselling education content $(n=300)$.

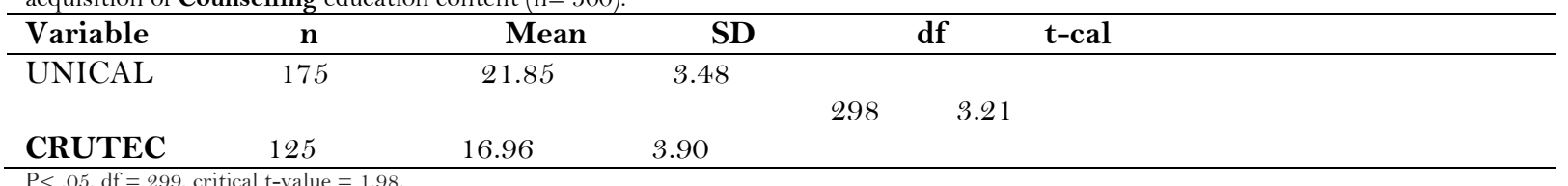

$\mathrm{P}<.05, \mathrm{df}=299$, critical $\mathrm{t}$-value $=1.98$.

The result presented in Table 6 showed that the calculated t-value of 3.21 is greater than the critical tvalue of 1.98 at .05 level of significance with 298 degree of freedom. The null hypothesis is rejected while the 
alternate accepted. This implies that interschool respondents' rating of availability and utilization of e-learning resources in counselling education differed significantly.

\section{Discussion of Findings}

This study attempted to investigate the extent to which trainee Counsellors of universities in Calabar area are aware of and utilize modern e-learning resources to enhance the acquisition of Counselling knowledge, attitudes, values and skills. The results of this study indicated that the awareness of e-learning resources by the subjects used for this study was quite high but rather low in terms of educational use. The results tend to agree with Eke (2011) who reported that it was very common to see students who have access to the internet use their time to chat with friends, watch movies and stay deep into the night communicating with internet friends in face-book, twitter, instagram, what sap, and pinging, etc. His finding also indicated that respondents rather than use such opportunity to gather materials for their educational development or utilizing it for educational purposes, invested it in less utilizable, non-educational purpose. Given these outcomes, it is obvious that they were aware of the availability of e-learning facilities such as e-library which could provide students with academic reservoir through which relevant academic materials could be accessed but very doubtful if they utilize them to acquire Counselling knowledge, skills and behaviours.

The results of this study also showed that the rating of availability, adequacy, currency and quality of elearning facilities such as e-library and internet cloud to be accessed by students was very low with wide range of interclass, inter-school and gender differences. These results are consistent with those of Philip (2003); Bamidele (2006); Ofodu (2007); Bates and Poole (2013); Kasse and Blunywa (2013) who in their various studies observed variations in the rating of availability of e-resources among respondents.

\section{Conclusions and Recommendations}

This study investigated awareness and utilization of e-learning resources for acquisition of counselling content among undergraduate would be counsellors in Universities in Calabar, Cross River State. Findings showed high awareness of e-learning but low utilization amongst respondents in the study. Although there were inter -class, -school and-gender variations, the rating of availability, adequacy, currency, quality and utilization of e-learning resources was rather low.

From the foregoing, it was recommended that:

i. Lecturers and students should be trained in appropriate skills in E-learning.

ii. Power supply should be adequate so as to enhance the use of e-learning in our universities.

iii. Government should provide e-learning technologies to Nigeria universities to equip their e-learning centres.

iv. Government should release fund to the universities for adequate funding of their e-learning centres.

v. Universities should employ capable computer experts to train Nigerian universities lecturers and students on the use e-learning technologies to deliver their lectures.

vi. Lecturers be given computers to enable them prepare their e-learning lectures and notes.

vii. Lecturers should be adequately motivated by the federal government and

viii. Both the universities and government should provide enough security to their e-learning centres in their institutions, to prevent stealing of the items therein.

\section{References}

Aguolu, C. C., \& Aguolu, I. E. (2002). Libraries and information management in Nigeria. Maiduguri: ED-Linform Services.

Asuquo, P. N. (2015). Career guidance: More than just advising. Calabar: University of Calabar Press.

Asuquos, P. N. (2017). Education, employability and worker-citizens of 21 st century Nigeria. In Joshua, Asuquo E̊ Petters (Eds.) Education for Careers in the 21 st Century Nigeria. Calabar: University of Calabar Press.

Bamidele, S. O. (2006). Development of modern ICT and internet system. In Agagu A. A. (ed.). Information and Communication Technology and Computer Application Abuja: Panof Press.

Bates, A., \& Poole, G. (2013). Computers and learning. San Francisco. New Jersey: Bass/John Wiley.

Eke, H. N. (2011). Modeling LIS students intention to adopt their E-learning: A case from university of Nigeria Nsukka.

Farrel, G., \& Shafika, I. (2007). Washington DC: info Dev/world bank. Retrieved from http://www.infodev.org./en/publication.353.tml.

Kasse, J. P., \& Blunywa, W. (2013). An Assessment of the e-learning utilization by a section of Ugandan Universities: Challenges, Success Factors and Way Forward.

Kozma, R. B. (2005). National policies that connect ICT-Based education. Reform to Economic and Social Development, 1(2), $117-158$.

Nwaoku, N. A. (2005). Gender attitude and commitments to teaching in tertiary educational institution in South-East Zone of Nigeria. Unpublished Ph.D. Thesis, University of Port Harcourt, Choba, Nigeria.

Ofodu, G. O. (2007). Nigeria literary educators and their technological needs in a digital age. Educational. Focus, 1(1), 2230 .

Onyejemezi, D. A. (1988). Educational technology in Nigerian education. Onitsha: Summer Educational Publishers Nigeria Limited.

Orr, D., Appleton, M., \& Wallin, M. (2001). Information literacy and flexible delivery: Creating a conceptual framework and model. The Journal of Academic Librarianship, 27(6), 457-463. 
Parks, E. (2013). The top teaching and learning. Ask international.com Retrieved 2013, 10-22.

Philip, B. T. (2003). A four local learning organization bench mark implementation model learning org. 10(2), 98-105.

Wilson, T., \& Whitelock, D. (1998). Changing roles; comparing face to face and on-line teaching in the light of new technologies. European Journal of Open, Distance and their E-learning, 1(1). 